Analyse eines Meteorsteins aus der Wiists Atacama. 313

klar war, konnte mittelst gebrannten Gypses zwar schnell geklärt werden, aber es erfolgte neben der Concentration des geringen Weingeistgehaltes auch eine widerwärtige Concentration des in dem Bier enthaltenen Bitterstoffs.

7) Untergähriges Bier, bald nach dem Eintritt der lebhaften Gährung mit gebranntem Gyps versetzt, klärte sich nicht und die Gährung dauerte fort.

8) Untergähriges Bier, das die rasche Gährung vollendet, also nur noch die Nachgährung zu bestehon hatte, wurde, mit gebranntem Gyps behandelt, nach dem Niederfallen des Gypses nicht sogleich klar, schien sich aber doch früher zu klären als dasselbe ohne Gypszusatz gebliebene Bier.

Hessel bemerkt, dass die angestellten Versuche vielleicht einen Fingerzeig geben über die Gründe, aus welchen die Alten den gebrannten Gyps anwandten, um den Wein milder und haltbarer zu machen und weshalb auch jetzt noch in Griechenland theils zur Verhütung des Sauerwerdens des Weines als Zusatz zum Moste, theils bei schon begonnener Säuerung des Weines als Zusatz zum Weine gebrannter Gyps angewendet wird. (Ann. d. Ch. u. Pharm. XXII. p.334-338). G.

\title{
Analyse eines Meteorsteins aus der Wüste Atacama.
}

Derselbe fiel 100 Leguas von der Küste Bolivias nördlich vom Hafen Cobiza, war sehr hart und zäh, von 7,89 specifischem Gewicht, und hatte in Höhlungen auf der Oberfläche bräunlich-weisse Kryställchen, die Kieselerde, Kalk, Eisenoxyd und Phosphorsäure enthielten. Nach Fr. Field bestand der Meteorstein in 100 Theilen aus

$$
\begin{array}{lr}
\text { Eisen } & 87,80 \\
\text { Nickel } & 11,88 \\
\text { Phosphor } 0,30 \\
\hline 99,98
\end{array}
$$

In verdïnnter Salzsäure war der Stein völlig löslich; Spuren von Schwefel waren nicht zu entdecken, dagegen solche von Kobalt. (Quarterly Journ. of the Chem. Soc. IX. No. 34. pag. 143. - Journ. f. prakt. Chem. Bd.69. Heft 3 und 4.)

H. $B$. 